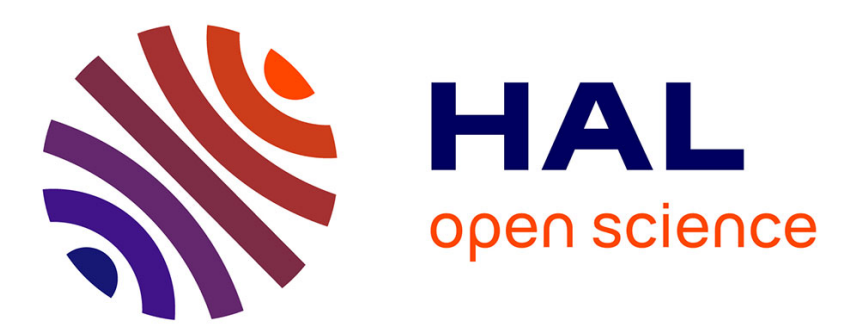

\title{
Retelling the Story of the 2017 French Presidential Election: The contribution of Approval Voting
}

\author{
Antoinette Baujard, Isabelle Lebon
}

\section{To cite this version:}

Antoinette Baujard, Isabelle Lebon. Retelling the Story of the 2017 French Presidential Election: The contribution of Approval Voting. 2020. halshs-02926773

\section{HAL Id: halshs-02926773 \\ https://shs.hal.science/halshs-02926773}

Preprint submitted on 1 Sep 2020

HAL is a multi-disciplinary open access archive for the deposit and dissemination of scientific research documents, whether they are published or not. The documents may come from teaching and research institutions in France or abroad, or from public or private research centers.
L'archive ouverte pluridisciplinaire HAL, est destinée au dépôt et à la diffusion de documents scientifiques de niveau recherche, publiés ou non, émanant des établissements d'enseignement et de recherche français ou étrangers, des laboratoires publics ou privés. 
UMR 5824

93. chemin des Mouilles 69130 Ecully - France

Maison de l'Universite, Bâtiment B 10, rue Trefilerie 42023 Saint-Etienne cedex $02 \cdot$ France

\title{
Retelling the Story of the 2017 French Presidential Election: The contribution of Approval Voting
}

\author{
Antoinette Baujard, Isabelle Lebon
}

\begin{abstract}
:
This paper proposes an alternative reading of the politics of the 2017 French presidential election, using an unstudied source of information on voters' preferences: experimental data on approval voting. We provide a new narrative of the election process and outcome. The principal approach for understanding the political context has for many decades been a distinction between left and right-wing political forces. We introduce a method for generating an endogenous political axis, and construct three indices so that we might understand how and why the conventional approach has become progressively irrelevant. We find no gender effect, but instead an age effect. Voters, especially those who belong to generations at the beginning or the end of their working life, use their vote in national elections to support radical change; and the younger the voters, the less they conform to a left-right axis. However, this desire for change does not represent a rejection of existing parties, as the official results would suggest. Rather, the approval results suggest an erosion in the voters' minds of barriers between distinct political camps, and between traditional and populist parties.
\end{abstract}

\section{Keywords:}

French Presidential election, Left-Right axis, Cultural Backlash, Political space, Approval voting, voting experiment

JEL codes:

C93, D72 


\title{
Retelling the Story of the 2017 French Presidential Election:
}

\section{The contribution of Approval Voting1}

\author{
Antoinette Baujard2, Isabelle Lebon3
}

August 27, 2020

\begin{abstract}
This paper proposes an alternative reading of the politics of the 2017 French presidential election, using an unstudied source of information on voters' preferences: experimental data on approval voting. We provide a new narrative of the election process and outcome. The principal approach for understanding the political context has for many decades been a distinction between left and right-wing political forces. We introduce a method for generating an endogenous political axis, and construct three indices so that we might understand how and why the conventional approach has become progressively irrelevant. We find no gender effect, but instead an age effect. Voters, especially those who belong to generations at the beginning or the end of their working life, use their vote in national elections to support radical change; and the younger the voters, the less they conform to a left-right axis. However, this desire for change does not represent a rejection of existing parties, as the official results would suggest. Rather, the approval results suggest an erosion in the voters' minds of barriers between distinct political camps, and between traditional and populist parties.
\end{abstract}

Keywords. French Presidential election, Left-Right axis, Cultural Backlash, Political space, Approval voting, voting experiment

JEL Codes. C93, D72

\section{Introduction}

In 2017 a centrist candidate won the French Presidential election in an unusual context. Hitherto the French Presidential election most often ended with a final duel between left and right.4 The election of a pro-European centrist candidate is generally thought to have gone against the tide in a context where all European countries are faced with the rise of populist authoritarian candidates (Norris and Inglehart 2019). However, the political positioning of the 2017 winner is only one striking feature among many in this election. The entire election was unusual, and some commentators even called it a "major earthquake" (Martin 2017). Rather than the consequences of "odd" or "contradictory preferences"

\footnotetext{
We wish to thank the whole team of "Voter Autrement", the members of the community Councils and all the volunteers who helped us to conduct the experiment on April 23, 2017 (see https://www.gate.cnrs.fr/ spip.php?article580\#Merci) . This research was made possible thanks to the support of the grants ANR DynaMITE (ANR13-BSH1-0010), ANR CoCorRICo-CoDec (ANR-14-CE24-0007), the IDEXLYON at the University of Lyon InDEpTH within Programme Investissements d'Avenir (ANR-16-IDEX-0005), and the University of Strasbourg Foundation. We owe a special debt of gratitude to Damien Bol for insightful comments on previous versions of this paper, and to Keith Tribe for the English editing of this version. The usual caveats remain.

2 Université Jean Monnet, Université de Lyon, GATE Lyon Saint-Etienne UMR 5824, 42023 Saint-Etienne Cedex 2, France. Orcid : 0000-0002-4156-7527. Email : antoinette.baujard@univ-st-etienne.fr

3 Normandy University, Unicaen, CREM, UMR CNRS 6211, France. Email: isabelle.lebon@unicaen.fr , corresponding author: Esplanade de la Paix, 14000 Caen, France.

Voting in a French presidential election usually involves a second-round majority runoff. A candidate wins outright in the first round if she obtains an absolute majority of the votes. If no candidate wins outright in the first round, then a second round is held between the two candidates who have the most first-round votes; the winner wins the election. While centrist candidates are more likely to win against any other candidate in a majority runoff, hence are likely to win at the second round of the election, it should be said that the re are few instances in French presidential elections where centrist candidates have made it to the second round.
} 
(Ferrand 2019), it can be considered to be one more brick in the restructuring of the partisan French political system (Haegel 2019).

This development seems to echo a more general movement away from the standard unidimensional reading of European politics. Ever since Meguid's interventions $(2005,2008)$ there has been broad recognition that the standard opposition of left and right is not the only relevant political dimension. By highlighting the behavior of competitors she shows that the strategies of mainstream parties have favored the electoral fortunes of new niche parties that reject the traditional class-based orientation of politics, do not conform to the existing lines of political division, and limit their appeal to one particular constituency (e.g. environment, immigration, regional claims). Kresi et al. (2006) have highlighted the cleavage between "winners" and "losers" in the current process of globalization and denationalization. Lachat (2008) showed that polarization reinforces ideological voting. While the prevalence of a leftright axis suggested that political preferences were structured by a single ideological dimension, Lachat (2018) maintains that the left-right continuum, together with other concrete political issues, is non-linear. Algan et al. (2018) examine the support for populist movements in a novel diagram opposing open to closed societies, and they show that the votes in this context can now be better predicted by individual subjective variables, such as well-being and interpersonal trust. Very generally, the approach to political understanding through the usual left-right-axis now seems passé, conventional political analysis has been upended (Tiberj 2013). The literature on this departure from a left-right axis focuses on the new dimensions, or how parties have adapted their strategies. We could be led to think that this development was discontinuous, a transition from 'before' to 'after', obscuring the process by which individual preferences for political candidates, and political institutions such as voting rules, have endogenously shaped this evolution. This gap needs to be filled.

This paper proposes an alternative reading of the political context of the 2017 presidential election, using a neglected source of information on voters' preferences: experimental data on approval voting. Approval voting allows each voter to support or not support each candidate; the winner is the candidate with the highest sum of approvals. Since they allow the expression of support for several candidates, approval ballots provide information about how individuals perceive each candidate in relation to the others; hence approval data offers an enriched map of individual political preferences. Compared with the probability settings of the Trielec programme used for the 2012 election (Tiberj et al 2013), approval voting does not just capture hesitation or indifference, but more generally an indifference class within the set of acceptable candidates. In experiments conducted simultaneously in four different cities around France during the first round of the French Presidential election on April 23, 2017, every voter from 13 voting stations was invited to cast a voluntary additional vote on their approval of all candidates after they had cast their official vote. We obtained 3,853 ballot papers from voters, indicating their official vote in the majority run off, their experimental vote on candidate approval, and other data including age and gender. 
Section 2 outlines the course of the electoral campaign up until election day, and Section 3 presents the experimental protocol. Using the prevalence of single approvals or co-approvals we suggest an alternative view of voters' perceptions of candidates, whether they could be considered as viable candidates or not, embodying the traditional voting pattern of representing the transformation of politics. This analysis shows how strategic voting within the official voting system both favored classical candidates until very recently, and then suddenly determined their exclusion. This property of majority runoff elections explains the impression of discontinuity in recent elections, and why official voting data fails to capture the nature of the dislocation which is at work in French politics. Section 4 discusses how the results from the experimental vote differ sharply from the standard interpretation given in relation to the official voting outcome of the first round of the election, and provides a drastically different view of the relative importance of parties. In Section 5, following the principle that two co-approved candidates are perceived as close, we represent the perception of a single political dimension by voter themselves. We build an endogenous axis on the basis of approval data. The axis obtained coincides with the standard left-right axis, proving that it still exists, but the measurement of non-conformity to this axis in the data shows how voters depart more or less from this standard view, according to their age or gender.

We claim that presenting the 2017 French presidential elections from the perspective of approval data allows us to provide a novel view of the political process. Establishing the existence neither of a surprising discontinuity, nor of a no less surprising proof of stability, the 2017 election is part of a trend that is common to many democracies, reflected in the growing attractiveness of candidates embodying change regardless of the political opinions of voters.

\section{The electoral campaign and its outcome}

The 2017 French Presidential election was held at the end of a five-year period when François Hollande, a socialist President, had succeeded Nicolas Sarkozy, a conservative President. François Hollande had beaten Nicolas Sarkozy in the second round of the 2012 election. One or two years before the 2017 election commentators anticipated another second round conservative-socialist confrontation, and maybe a Hollande-Sarkozy re-match (Rose 2016). The only feature thought likely to disrupt the usual switch between left and right parties was the chance that the populist right candidate, Marine Le Pen, could possibly reach the second round instead of either the socialist candidate or the conservative candidate. Her ability to reach the second round was seen as the only significant unknown element in the 2017 election. But a number of things happened and altered the course of the campaign. 
The socialist and the conservative parties each hold a primary election, open to all voters who have declared themselves to be their supporters, to determine who shall be their candidate. 5 In both cases they use the same voting rule as for the French Presidential election: a two-round plurality vote. These two parties have dominated French politics for some forty years, and turnout in the primary elections to select a candidate for the Presidency remains relatively high. In November 20164.3 millions voters participated in this way in the primary election for "the right and center" - even 4.4 millions in the second round. This represents more than $11.5 \%$ of the voters taking part in the first round of the 2017 Presidential election. The outcome for each party had been predicted neither by political observers nor by polling organizations. The former President, Nicolas Sarkozy, only reached the third position in the first round of the conservative primary. An outsider, François Fillon, the former Prime Minister under the Presidency of Nicolas Sarkozy, was the clearly front-runner at the first round. He was followed by Alain Juppé, who had been considered the front-runner of the party's slate of candidates; and François Fillon finally beat Juppé in the second round with more than $68 \%$ of the votes. François Fillon's victory positioned the conservative party, «les Républicains », strongly on the right.

After being delayed by President Hollande's hesitancy in deciding whether he would run, the primary of the leftist parties took place in January 2017. Given his low level of popularity, François Hollande finally decided against running for a second term, giving way to his Prime Minister, Manuel Valls, for the primary. But this was finally won by Benoît Hamon, from the left of the socialist party.

Besides these two candidates, there were three important outsiders in the Presidential race. Marine Le Pen, president of the largest right-wing populist party, Le Front National, decided to run for election in January 2016. Jean-Luc Mélenchon, sometimes considered as a "leftist populist", refused to participate in the leftist primary election and entered the Presidential competition in February 2016 under the banner of «La France Insoumise», a party created to support his candidacy. A third outsider who decided to run for the Presidential election without going through any primary election was Emmanuel Macron. He declared his candidacy in November 2016, just before the French Primary election for the Right and Centre. He had just resigned from his position as Minister of the Economy, Finance and Industry. He defined himself as a centrist candidate, neither right or left, and created the movement «En Marche» from scratch in the Spring of 2016. A series of events offered him unexpected opportunities. The two primary elections had produced one candidate on the far right of his party and one on the far left, leaving a political space in the center. Faced with this novel situation François Bayrou, the former centrist candidate of the 2007 and 2012 elections, declined his candidacy and decided to support Emmanuel Macron.

\footnotetext{
5 Two primaries were held before the 2017 election: the first, the French Primary for the Right and Center, took place in November 2016 and was organised by three parties: Republican, Christian Democrat and the National Center of Independents and Farmers. The second, the 2017 Citizen's Primary, was held in January 2017 to select a presidential candidate for the Socialist Party and its allies, in which many leftist parties ultimately failed to participate. 
The most unexpected event happened early in 2017. While the conservative candidate, François Fillon, had won the «Right and center» primary election on the basis of a platform focused on moral rigor, he suddenly became involved in a number of financial scandals and was formally charged. He decided to maintain his candidacy, although his position had been undermined. On election day Fillon was still considered to be a viable candidate, insofar as his chance of being in the second round could not be excluded. Three other candidates were also considered to have viable prospects: Marine Le Pen, Emmanuel Macron and Jean-Luc Mélenchon. Polls clearly indicated that that Benoît Hamon was not expected to reach the second round: his forecast election numbers kept decreasing, poll after poll. Meanwhile, the forecast support for Mélenchon and Macron was progressively increasing. The other six candidates had never been likely to reach the second round: Nathalie Arthaud (Lutte Ouvrière, extreme left), François Asselineau (Union Populaire Républicaine, anti-EU right), Jacques Cheminade (Solidarité et Progrès, unclassifiable), Nicolas Dupont-Aignan (Debout la France!, anti-EU right), Jean Lassalle (Union pour la Démocratie Française, centrist), and Philippe Poutou (Nouveau Parti Anticapitaliste, extreme left).

Just before the election the polls were predicting around 18-25\% of the votes for each of the four viable candidates, such that there was a great level of uncertainty about the eventual outcome. The first round was held on April 23rd, 2017. The scores of the four viable candidates were indeed close to each other: Macron (24.01\%, qualified for the second round), Le Pen (21.30\%, qualified for the second round), Fillon (20.01\%) and Mélenchon (19.58\%). They represented $84.9 \%$ of the votes cast. The remaining votes were distribute among the other seven candidates: Hamon (6.36\%), Dupont-Aignan (4.70\%), Lassalle (1.21\%), Poutou (1.09\%), Asselineau (0.92\%), Arthaud (0.64\%), and Cheminade (0.18\%). The second round took place on May 7, 2017; Macron beat Le Pen, receiving 66.10\% of the votes cast.

These results were not that surprising, in the sense that they were in line with the polls. However, they did represent a genuine rupture in French political life. Firstly, neither of the two parties that had dominated French politics for decades, the socialist party and the conservative party, participated in the second round. We have already observed that this was been a profound change, since subsequently the electoral basis of these parties appeared to fade away, as confirmed by the 2019 European election and an important number of individual defections since. Secondly, the outcome of the first round shows clearly that the two populist candidates, Le Pen and Mélenchon, became major figures in French politics, and that the possibility of their future election could not be ruled out. Thirdly, two out of the four viable candidates, Macron and Mélenchon, represented new political parties created expressly for the election. Last but not least, the Presidential election produced a candidate who refuses to position himself on the usual left-right schema. This might even be a substantial reason for his success.

While many commentators considered the French presidential election to be an exception in European and world politics, it is our own view that this election is proof of a common movement in the profound dislocation of politics.

5 
Several possible explanations can be provided. Among others, a substantial literature commented on the legacy of Sarkozy's strategy for the conservatives of adopting the policies of right populist parties as his own, yet refusing any agreement with them, notably in the 2007 and 2012 elections. Rather than attracting the votes of right populist voters, this tended to normalize the ideas supported by the latter, incorporating such policies in French political debate. This resulted in a "de-demonization" ("dédiabolisation") of the populist right party "Front National", which also as a consequence had the good fortune of never being exposed to the usual seepage of support once they took some kind of political or administrative responsibility. In the circumstances, this argument over Sarkozy's strategy can explain the rise of an extreme right party, and maybe also part of the decrease of the conservative party, but not the rise of a new centrist party. In contrast with the standard reading of this election, which considers that this election represented a historical discontinuity, we instead wish to offer a new argument, based on the voting rule. The two round plurality rule allows each voter to select only one candidate. This property has tended to exaggerate the perception of a dramatic change in voters' behavior. The fact that new political parties became viable does not in any way imply that voters now reject the older parties, which remains to be confirmed or invalidated. The results of a voting experiment under approval voting conducted during the first round of the French presidential election in four different cities in France provide additional information on the political preferences of French voters beyond their vote cast in the official election.

\section{Approval voting suggests an alternative perspective on the public perception of candidates}

Under the two round plurality vote voters are forced to select a unique candidate. This leads voters to think strategically when voting; they have no incentive to vote for a non-viable candidate because this would be unlikely to influence the outcome of the election. The absence of a vote in favor of such a candidate should not interpreted as a rejection or evidence of electoral preferences against him/her, but as a rational choice taking account of available information. Many voters select from among their favorite candidates the one who is most likely to make it to the second round. Others will even forego their ability to support a favorite candidate to vote for a viable candidate. A candidate whose polls are predicting she or he will fail to pass to the second round will suffer a progressive loss of support. By contrast, approval voting allows voters to support as many candidates they wish, and the candidate who attracts most approvals wins. Voters have the opportunity to express their support for any candidates without any constraint affecting their expression, as in the official voting rule. Approval ballots capture valuable information about which candidates voters would be happy to see win (when they approve of the candidate), and whom they would not (when they do not approve of the candidate). Hence approval 
voting data provide more reliable and less biased information about political preferences, compared with the two-round ballots which to a large extent are governed by strategic behavior.

On April 23 2017, during the first round of the election, we ran a voting experiment in four different cities (see Annex A and other references for the presentation of the protocol). We collected 3,853 ballots of approval voting, of which 3,812 were usable (see Table B.1 in Appendix B). Such approval data offers a fresh perspective on how voters viewed the candidates as compared with their official ballot. Although we have a large number of observations, our sample was not meant to be representative; voters were invited to participate in the experiment on a voluntary basis, and the cities where the experiment took place are not necessarily representative of the French electorate. But consideration of their official votes allows is to measure the political bias of our sample, and to adjust our experimental outcomes to the national result (see Table B.2 in Appendix B). We are able to correct this bias and provide significant results and interpretation. On the other hand, although the genuine diversity of the experiments' locations was meant to guarantee a plurality of participants in many dimensions, another bias concerns the demographic and sociological representation of our sample; given a lack of information for each location we have not been able to correct for this representation bias.

The experimental protocol was designed to be able to compare, for every voter, their official vote and approval vote, such that we are able to study their opinions and support for each electoral platform, and characterize how voters for these platforms perceive the other candidates. In particular, we are able to check whether a high score for certain candidates (and low scores for certain other candidates) at the official vote correspond (or not) to the genuine popularity (or lack of it) of these candidates in voters' preferences. Analysis of this kind might help understanding of certain important facts in this Presidential election: is the historically low score of Hamon evidence of a definitive rejection of the Socialist Party? Do the historically high scores of the right and left populist parties reflect broad support for their ideas? How can we interpret the election of the novel centrist candidate Macron?

We derive information about the characteristics of the candidates by distinguishing between the voters who approve them and who voted for them, and those who approved them but did not vote for them under the official voting rule.

We can first measure the proportion of mono-approval, i.e. the extent to which voters continue to support only their official ballot candidate, while the voting rule allows them to support several. When this happens voters do express something truly significant, that given the political offer they would support no other candidate but the one they had selected from the field. 
Table 1. Share of unique approvals (in \% of the official votes in favor of the candidate)

\begin{tabular}{|l|l|l|l|l|l|l|l|l|l|l|l|}
\hline & EM & MLP & FF & JLM & BH & NDA & JL & PP & FA & NA & JC \\
\hline $\begin{array}{l}\text { Unique } \\
\text { Approvals }\end{array}$ & 21.11 & 22.73 & 22.73 & 13.61 & 17.69 & 14.95 & 13.04 & 10.34 & 18.52 & 12.50 & 0.00 \\
\hline
\end{tabular}

To be read as: the share of participants who did vote for NDA in the official vote and selected only NDA in the approval voting is $14.95 \%$.

What is striking in Table 1 is the low share of unique approvals for their official vote. Whichever the candidate, at most $22.73 \%$ of the voters have a unique candidate, and much less for some candidates. This clearly reveals that voters do not have a segmented view of politics. Most voters would very likely consider seriously supporting a number of possible candidates if the voting rule gave them the opportunity to do so.

Beyond this observation, differences among candidates are significant. 3 out of 4 of the viable candidates (Macron, Le Pen, Fillon) have the highest shares of unique approval (ranging from 21.11 to $22.73 \%$ ). The fourth (Mélenchon) on the contrary received a smaller share of unique approvals (only 13.6\%).

On the other hand, let us consider the voters for other candidates. The approvals of candidate $i$ 's voters by the voters of other candidates indicates how $i$ attracts co-approvals, hence how $i$ is appreciated in a broader public opinion.

Table 2. From official votes to approvals (in \% of voters at the official vote)

\begin{tabular}{|l|l|l|l|l|l|l|l|l|l|l|l|}
\hline & EM & MLP & FF & JLM & BH & NDA & JL & PP & FA & NA & JC \\
\hline EM & 96.84 & 2.13 & 18.66 & 32.57 & 53.60 & 7.35 & 5.38 & 8.70 & 2.06 & 4.58 & 2.06 \\
\hline MLP & 21.02 & 98.30 & 27.84 & 23.30 & 6.82 & 35.80 & 5.68 & 7.39 & 9.09 & 6.82 & 2.27 \\
\hline FF & 48.80 & 22.97 & 91.87 & 9.57 & 8.37 & 29.19 & 7.18 & 2.39 & 5.02 & 1.67 & 2.63 \\
\hline JLM & 22.45 & 3.23 & 3.74 & 98.30 & 65.14 & 6.04 & 8.76 & 40.31 & 5.44 & 19.64 & 5.61 \\
\hline BH & 43.08 & 1.58 & 5.43 & 56.57 & 97.37 & 5.08 & 5.43 & 25.22 & 3.15 & 15.24 & 2.98 \\
\hline NDA & 35.51 & 30.84 & 25.23 & 22.43 & 20.56 & 99.07 & 9.35 & 3.74 & 11.21 & 2.80 & 8.41 \\
\hline JL & 30.43 & 13.04 & 4.35 & 21.74 & 17.39 & 17.39 & 86.96 & 21.74 & 4.35 & 8.70 & 8.70 \\
\hline PP & 20.69 & 6.90 & 3.45 & 55.17 & 48.28 & 3.45 & 3.45 & 100 & 13.79 & 24.14 & 3.45 \\
\hline FA & 22.22 & 22.22 & 11.11 & 40.74 & 11.11 & 18.52 & 7.41 & 25.93 & 88.89 & 7.41 & 14.81 \\
\hline NA & 18.75 & 0.00 & 0.00 & 56.25 & 31.25 & 0.00 & 0.00 & 62.50 & 6.25 & 93.75 & 6.25 \\
\hline JC & 25.00 & 0.00 & 0.00 & 25.00 & 50.00 & 50.00 & 25.00 & 0.00 & 25.00 & 0.00 & 100 \\
\hline
\end{tabular}

To be read as: Among $i$ 's voters, what is the share who have voted for $j$ too? The share of participants who voted EM (in row) at the official vote and also approved MLP (in column) is $2.13 \%$. The share of participants who voted for MLP (in row) at the official vote and also voted for EM (in column) is $21.02 \%$.

Table 2 shows that Mélenchon voters in the official vote were very likely to have also approved the Socialist Party candidate Hamon (65.14\%), or the candidate of a small extreme left party, Poutou (40.31\%), which explains his low proportion of mono-approvals. This suggests that votes that could have been for one or the other were given to Mélenchon because of his viable candidate status.

More generally, the figures in Table 2 allow us to compare the results of the official vote and of the approval vote. These data improve our understanding of voters' opinions about the different candidates. The diagonal of the table deviates from 100, meaning that some voters did not approve the candidate for 
whom they voted in the official vote. Of course, in some cases we cannot exclude that this represents errors in completing the experimental ballot papers. But in other cases, particularly where in the official vote Lassalle or Asselineau were chosen, this might be a protest vote, and voters were able to vote for a candidate who they did not actually support.

Table 2 allows us to identify different types of candidates. To establish such a typology we shall consider the scope of various "major" and "minor" candidates (on the classification of candidates, see Baujard, Igersheim and Lebon 2020). Major candidates are the 4 viable candidates, plus the two candidates who got a significant number of votes at the official vote, Hamon and Dupont-Aignan. Among these major candidates, we can distinguish two groups, as suggested by Darman et al. (2017). One set of major candidates - Macron, Mélenchon and Hamon, attracted significant support from the voters for other candidates; we call these "popular candidates". The other set of major candidates - Le Pen, Fillon and Dupont-Aignan - are only approved by a lower share of the voters outside their own electorate; we have called these "polarizing candidates".

By contrast, all minor candidates taken together only received around $4 \%$ of the official vote. 6 They can also be distributed into two groups. One set of minor candidates belong to old, well-known and politically "well-identified" parties: Arthaud and Poutou are two extreme-left candidates who attracted approvals from those who voted for those major candidates who are closer to their position. The three other minor candidates, Lassalle, Cheminade and Asselineau, are hardly known to the public, and most voters are unfamiliar with their political position; we can call them the "uncovered candidates", because they received low media coverage. They are mostly associated with a protest vote; they are very rarely approved by the electors of the other candidates (see Table 3), while their own voters are very few.

Let us consider the major candidates in greater detail, and what their experimental scores tell us about the 2017 political context. Macron, the future winner of the election, had real support among the voters of all of his opponents: from $18.75 \%$ from Arthaud's voters to $48.8 \%$ from Fillon's voters. Being at the center attracts a range of voters, from the left and from the right, hence from the Socialist Party and the conservatives of the Republican Party. What is more striking is his capacity to attract approval from those voting for the extreme and/or populist candidates, as well as from protest voters. A consequence of his adopting a position outside the constraints of the historic parties, Macron was perceived as a candidate of change. Considering the share of approvals among each candidate's voters and the share of votes received by each candidate in the official election, we can estimate that $31.6 \%$ of those who voted for other candidates also approved of Macron (see Table 3). Beyond his own voters, Macron benefited from genuine broad support in public opinion.

Considering the low number of official voters for minor candidates at the national election and among the
participants in the experiment, the results associated with those who voted for these candidates should be interpreted provisionally, since such low numbers are likely to induce greater sample sensitivity.

9 
Table 3. Average Approval by other candidates'voters (in \%)

\begin{tabular}{|c|c|c|c|c|c|c|c|c|c|c|c|}
\hline & EM & MLP & FF & JLM & BH & NDA & JL & PP & FA & NA & JC \\
\hline $\begin{array}{c}\text { Approval } \\
\text { nonOFF }\end{array}$ & 31.60 & 9.82 & 16.08 & 26.10 & 32.94 & 18.09 & 6.67 & 14.88 & 5.57 & 8.32 & 3.51 \\
\hline
\end{tabular}

To be read as: $31,6 \%$ of the voters who did not vote for EM at the official vote approved of him. Note : The results are corrected by the official distribution of votes cast.

Voter behavior vis-à-vis Mélenchon is much more surprising. His first-round score (19.58\%) may seem very high at first sight, given his positioning on the far left. Yet our experiment shows that, just like Macron, he enjoys strong support among the voters of almost all the other candidates. More than half of the voters of the other left-wing candidates approved Mélenchon; so did more than a fifth of Le Pen's voters $(23.30 \%)$, ranked on the far right. The only voters who were reluctant to approve Mélenchon were those supporting the conservative candidate Fillon (9,57\%). This supports the idea that, like Macron, Mélenchon is also perceived as a candidate in favor of the change that many voters hope for. And this despite the deep disagreement between these candidates over the European question: Mélenchon expresses distrust towards Europe, while E. Macron is a clear pro-European candidate. This attraction for candidates who embody novelty resembles other movements elsewhere in Europe where emerging parties have supplanted historical parties, especially on the left of the political landscape. For example, the emergence of Podemos in Spain coincided with the partial collapse of the old Socialist Party (PSOE), or how the arrival of Syriza in Greece led to the fall of an established Pasok. It is tempting here to draw a parallel with the very low score of the Socialist Party candidate for the 2017 French presidential election. While the official vote indicates a loss of influence on the part of historical parties, the experimental data argue against the view that the continuing fall of votes cast for the French Socialist Party is indicative of a general fall in support for the party. Nearly one-third of those who voted for other candidates in the official ballot would have supported Hamon if another voting rule had made this possible (see Table 3); and if we focus on the voters approving both Macron and Mélenchon, a majority of these would likewise have approved Hamon. Clearly, Hamon found himself caught between these two candidates, and trapped by the strategic voting behavior. In the specific context of the first round according to a plurality rule in the election on April 23rd Macron and Mélenchon were often preferred to Hamon purely for strategic reasons. Whereas the socialist party used to be somewhat protected by strategic behavior from which it often benefited, it now seems to have become a victim of rational voting behavior.

Our analysis instead supports the following claim: although there was no deep and widespread rejection of the traditional parties as has often been claimed, the reflex that always brought most voters back to these parties regardless of the candidates who represented them has disappeared. In the context of a decline of the older loyalist reflex in favor of a traditional party, emerging movements are likely to win. Hence the temptation of certain personalities to bypass the cumbersome traditional political apparatuses, 
relying on a small group and using new media to communicate. The emergence of charismatic personalities and new approaches to politics accelerates the electoral decline of traditional parties under mono-nominal voting procedures.

The three major polarizing candidates, all of them right-wing, had a much narrower voter support basis than the socialist candidate. They are mainly supported by each other's voters, and so from among supporters for right wing parties.7 This is an important observation, given that their sensitivities are nonetheless substantially different, and their principles are supposedly incompatible in certain perspectives: e.g. somewhat pro-European (Fillon) vs. sovereignists populist right (Le Pen or DupontAignan). Thanks to our data we can demonstrate the importance of the joint approvals, which show a real porosity between electoral bases. This groundswell continues, and is likely to lead in the future to a reorganization of parties on the right.

More generally, the data in Table 2 also bring to light an asymmetrical left-right trend in voters' approval behavior: while the voters of the major candidates on the right are likely to approve leftist candidates, the reverse is either not true, or is less marked. As a result, the shares of approvals for right candidates among other candidate's voters is much lower than that obtained by leftist candidates (see Table 3 ). This has to be explained. Given the rules of two round plurality voting, the major candidates may be encouraged to choose divisive positions at the first round (See Meguid 2005, 2008, Ehrhard 2016, Baujard \& Igersheim 2011, Baujard et al. 2014) in order to qualify for the second round. Clearly, rightwing parties are banking on a narrow, but solid, political niche. If such a candidate is successful at the first round, a more consensual attitude will be adopted at the second round. One good way to win the election is to have an opponent in the second round who is even more divisive, e.g. from the extreme right. The relatively large number of unique approvals obtained by Le Pen and Fillon tend to validate this hypothesis (see Table 1). It is fair to say that, if these positioning strategies make sense in the context of the two-round plurality vote, such positioning would be anticipated to be much less effective with an approval voting rule.

\section{Approval voting generates novel results, new winners and losers}

As established above, voter behavior vis-à-vis the various candidates allows us to anticipate that an approval vote will not result in the same ranking as that of the first round of the official vote. To make such comparisons we need comparable data and to avoid any confusion between discrepancies that result from the voting rule, and those that simply result from sampling bias. For instance, in the experiment greater or lesser voter participation according to opinions may compromise proper interpretation. Hence

\footnotetext{
$7 \quad$ They also attract approvals given by some of those who in voting for a minor candidate appeared to be registering a protest vote, but as already noted, we must consider these cases with caution given their low number.

The term "sovereignty", in contemporary French politics, draws attention to the ability of the State to govern and exercise its power in a context of globalization, and EU institutions.

11
} 
we use corrected data. A weighting coefficient is applied to the ballots such that the distribution of the official votes in the sample reproduces the distribution of votes cast at the national level (see Table B.2 in Appendix B). We do not obtain an uncontroversial representative sample for all uses, but it does eliminate the main structural effects and allows the comparisons we now need.

Table 4. Corrected data of approval voting (in \% of voters) and comparisons of rankings between the official and the approval vote.

\begin{tabular}{|c|l|c|c|c|c|c|c|c|c|c|c|}
\hline & EM & MLP & FF & JLM & BH & NDA & JL & PP & FA & NA & JC \\
\hline $\begin{array}{c}\text { Official } \\
\text { ranking }\end{array}$ & 1 & 2 & 3 & 4 & 5 & 6 & 7 & 8 & 9 & 10 & 11 \\
\hline $\begin{array}{c}\text { Approval } \\
\text { ranking }\end{array}$ & 1 & 5 & 4 & 2 & 3 & 6 & 9 & 7 & 10 & 8 & 11 \\
\hline $\begin{array}{c}\text { Approval } \\
\text { results }\end{array}$ & 47.26 & 28.66 & 31.25 & 40.24 & 37.04 & 21.90 & 7.64 & 15.80 & 6.33 & 8.87 & 3.69 \\
\hline
\end{tabular}

To be read as: MLP is second in the official ranking (second column) and fifth in the ranking of approval voting. She has been approved by $28.66 \%$ of the voters.

Figure 1. Comparisons of rankings between official and approval vote, on the basis of corrected data.

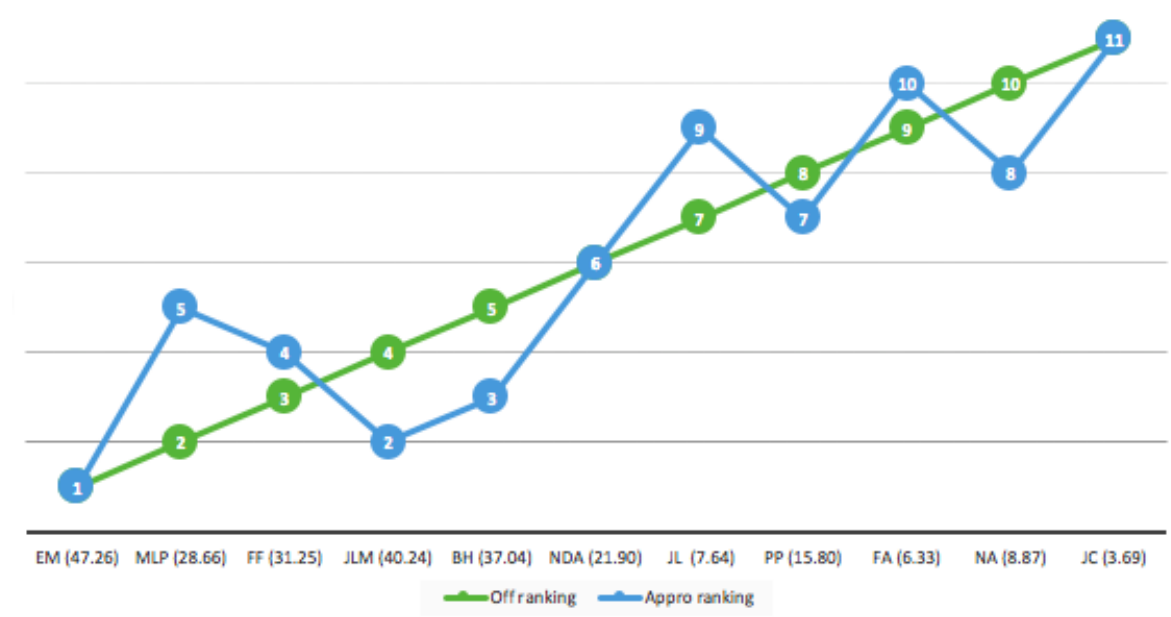

To be read as: MLP is second in the official ranking (in green) and fifth in the ranking of approval voting (in blue). She has been approved by $28.66 \%$ of the voters.

The winner of the 2017 presidential election is also the winner of the experimental election (unlike the 2007 election, see Baujard and Igersheim (2011)). However, the experimental ranking is significantly different from the ranking of the first round of the official French Presidential election (see Table 4 and, for a summary layout, Figure 1). As expected, the ranking progression or decline per candidate depends on which is her/his type of candidate: major polarizing or popular, minor well-identified or uncovered (see above). In the experimental ranking it is striking that every major popular candidate is ranked before every major polarizing candidates, who are themselves ranked before all minor well-identified candidates, who are then in turn ranked before all uncovered protest candidates.

Candidates who attracts a great deal of approvals from their opponents' voters are necessarily favored by approval voting as compared with those having a narrow electoral base (in accordance with Baujard 
et al. 2014 analysis). As a result, Mélenchon and Hamon are ranked before Le Pen and Fillon according to the approval vote, i.e. the reverse of the official vote.

A second notable feature is that there is a gradient in voter rejection or voter support in respect of the various polarizing or popular candidates. As a result, the ranking between Fillon and Le Pen is also reversed; and Le Pen, who is second in the official vote and qualified for the second round, was only ranked fifth under approval voting. This discrepancy between the two voting outcome reveals Le Pen's niche strategy of reaching the second round through polarization and a strong distinction from other electoral bases. This logic also explains the poor score that she achieved in the second round of the official election against Macron, who was in contrast strongly supported by every alternative electoral basis.

The relative ranking of minor candidates also changed from the official vote to the approval vote. Poutou and Arthaud are favored by the approval rule as they are now respectively 7 th and 8th. Taking the official vote as a benchmark, their better ranking in the approval vote clearly results from significant support from the voters for the leftist major candidates, in particular from Mélenchon's voters. From another point of view, this improvement reveals that Poutou and Arthaud are penalized in the official poll by Mélenchon, since the latter is a viable candidate. Some of the voters who could have voted for either Poutou or Arthaud may have voted for Mélenchon for strategic reasons, because they might reasonably expect he could reach the second round.

Interestingly, approval vote here seems to favor leftist candidates; or, to be more precise, to favor all candidates positioned from the far left to the center by improving their ranking at the expense of that of right-wing candidates. This observation is not specific to the 2017 presidential election. The same feature had been observed in 2012 (Baujard et al. 2014) and in 2007 (Baujard and Igersheim 2007). This regularity seems to result, firstly, from the fact that center or left-wing candidates are more numerous than alternatives (8 out of 12 in 2007, 6 out of 12 in 2012, and 6 out of 11 in 2017), which disperses left votes relatively more in the official ballot. Secondly, voters for left-wing candidates are more likely to co-approve other left-wing candidates than right-wing voters are. Thirdly, we observe that voters for the right-wing candidates more frequently support left-wing candidates than the converse (see below).

We can also provide some explanations for these asymmetric features, considering voters' aspirations and candidates' programs. Tax and social justice can be seen as the main issue for leftist candidates in the election, but this issue is both likely to deter some leftist voters and to attract some voters of the right. Conversely, voters who have chosen a left-wing candidate would be less interested, or even deterred, by the specific ideas of the right, e.g. on the liberal State vs. welfare state polarity from Conservative parties, or the strict migration policies advanced by the populist and parties. Moreover, right-wing voters may be sensitive to some but not all of these ideas, leading to the lowest proportion of cross-support between right-wing candidates compared with cross-support among the left-wing candidates. Among other things, this results in an absolute advantage for left-wing candidates in the 13 
approval vote; however, it would not necessarily follow in the official ballot. Indeed, the positioning of the different candidates, and in particular that of the candidates on the right, would adapt to this new rule. The left-wing bias of approval voting is not a property of the rule itself, since it is primarily driven by the contemporary French political context.

\section{Approval voting creates an alternative perspective on French politics}

From the standard perspective of the political landscape organized around a left-right axis, it makes sense to expect that voters of a leftist candidate would also approve other leftist candidates, and that voters of a rightist candidate would also approve other rightist candidates. Contrary to these expectations, we have observed that rightist voters may also approve leftist candidates, and provided an explanation for that. But this is only a small part of the information that approval data gives us about voter preferences. To go deeper into the analysis, let us consider all the co-approvals expressed by all voters, something that gives us very detailed information on their preferences. Table C.1 in Appendix C summarizing these co-approvals highlights the significant proportion of unexpected co-approvals, which might question the standard representation of French politics. But in order to extract the dominant representation from our data and make this representation comparable with the standard perspective, we wish to preserve the unidimensional form of a political axis by arranging all candidates along a continuum. From this we can explore the extent to which voters conform to it, or distance themselves from it.

Rather than viewing French politics through the prism of an exogenous left-right axis, we are able to construct a political axis based directly on the choices of voters: the axis we here propose derives endogenously from voters' perceptions of politics, as revealed by their co-approvals. At the individual level, since approvals offer the voter the opportunity of simultaneously supporting every candidates a voter favors, an approval ballot provides for each voter a separation of candidates into two distinct groups: the set of candidates which the voter would support in the election, and the set of those she or he would not support in the election. An elector would approve only candidates whom she or he considers sufficiently close to her or his own ideas (or closer than alternative candidates), and disapprove those she or he considers sufficiently far away (or relatively further away). All candidates among the set of approved candidates are closer to one another according to her or his mind than candidates outside this set. Hence her or his approval ballot informs us about that voter's perception of politics.

For each voter, an axis is an ideal representation of her or his perception of politics if all the candidates she or he has approved are located next to each other (concretely with no gap in between), and if all other candidates are either further right or further left. There are as many potential axes as there are possible arrangements of the candidates, but the aggregation of these individual preferences serves to identify the best of all possible axes. For all voters, an axis is the best representation of their perception 
of politics if it minimizes the sum of unapproved candidates inserted between approved candidates by every voter. We compute a score for each possible axis by counting the number of unapproved candidates who are placed between approved candidates on the totality of the ballots. Note we here use weighted ballots to reproduce the official distribution of the votes (see Table B.2 in Appendix B). The best obtained axis, i.e. the axis giving the lowest score, is shown in Figure 2.9 This axis, and its exact converse, have the same score. However, by convention we choose the version in which the candidates usually considered as left (right) are located to the left (to the right) of the axis.10

Figure 2: Political axis of the 2017 French presidential election, constructed endogenously from approval data

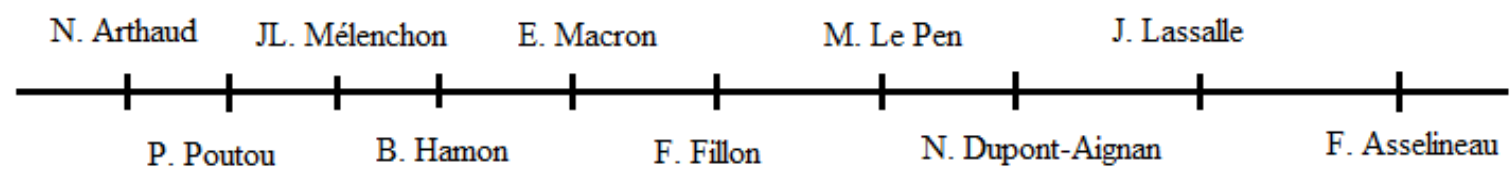

To be read as: Hamon is close to Mélenchon and to Macron, but Mélenchon is closer to Hamon than Macron. In addition, the metric distance between two contiguous candidates on the axis is inversely proportional to the average of the co-approvals between these two candidates.

An outstanding feature of the endogenous axis is that it exactly corresponds to the standard representation of the political landscape. Constructed solely from the approval data of voters, it reproduces almost perfectly the usual positioning of the 2017 Presidential candidates on a left-right axis. We now need to understand the extent to which this axis obtained by endogenous methods generally conforms to the opinions of the electorate. As already noted, the phenomenon of non-conformity with the endogenous axis is relevant information about the quality of the left-right axis as an image of the political landscape. This phenomenon, and more generally the electorate's vision of political life, are captured by our three indices.

The proportion of mono-approvals measures the share of ballots in which only one candidate is approved: failing to express support for several candidates, these voters are equally compatible with any axis, and therefore did not influence the construction of the axis. This electorate is matches the usual voting system for a single candidate. $21.79 \%$ of the corrected total weight of voters approved only one candidate; and the choice they express neither supports nor contradicts the left-right approach to politics. Conversely, the proportion of multiple-approvals is the relevant basis for studying the phenomena of non-conformity: in our data, they represent $78.21 \%$ of the voters.

${ }_{9}$ For more details on the algorithm itself, see Lebon et al 2017.

${ }_{10}$ Notice that only 10 of the 11 candidates are positioned on this axis. Cheminade, was too rarely approved to determine a robust and reliable position for him on the basis of our data. For similar reasons, the position of Lassalle may come as a surprise. Lassalle here appears quite extreme, although this candidate comes from the centrist party. But he is also a minor candidate, even an uncovered candidate. As such, he experiences a centrifugal effect typical of the axis determination method. Knowing that the candidates who are most often approved by voters and who also approve of Lassalle are Hamon, Macron and Mélenchon (see Table C.1 in Appendix C), Lassalle is pushed towards the end of the axis because of weak support. Hence his positioning should be interpreted as a result of a low intensity of support rather than any genuine positioning on the extreme right. For this sample, and once Cheminade was excluded from the axis, Lassalle is the only candidate who suffers from this type of potential interpretive ambiguity. 
Hence the axis is constructed from the remaining 2981.5 (weighted corrected) ballots for which several candidates are supported simultaneously. Among these, only 57\% ballots are perfectly in line with our best axis. We can call this feature the axis conformity rate; conversely, the axis discrepancy rate denotes the frequency among voters of non-conformity to the best possible left-right axis. The axis discrepancy rate amounts to $43 \%$, i.e. $43 \%$ of multiple-approval voters do not fit into the left-right pattern, in that one or more unapproved candidates intervenes between the approved candidates.

The axis score measures the intensity of this non-conformity, i.e. the number of non-approved candidates inserted on average between approved candidates along the axis. For a particular ballot, the score ranges from 0 (when the ballot complies with the axis) to $n-2, n$ representing the number of candidates for the axis. As we only consider 10 candidates out of 11 , the maximum score is 8 , which captures the case where the two extreme candidates are approved and no others: 8 is then the number of not-approved candidates along the axis between two approved candidates. The axis score is the average score considering every mutiple-name ballots. The more unapproved candidates in between approved candidates, the higher the score. Over all approval ballots with co-approvals, i.e. considering all the ballots that were used to create this axis, the axis score is 0.98 . When we focus on the $43 \%$ of multiapprovals ballots which do not comply with the best axis, the average number of candidates between approved candidates on the line rises to 2.29 , which reveals a significantly different view of the political landscape on the part of these voters. As highlighted by distances between candidates in Figure 2 (see Table C.2 in Appendix C) there is a much greater proximity between candidates on the left than between those on the right of Macron. This means that, to the right of the axis, the contiguous candidates are less often co-approved by voters than the leftist candidates. Voters who have co-approved at least one rightwing candidate are therefore at the origin of more non-conformities compared with the endogenous axis. To improve our understanding of these nonconformities to the endogenous axis in the case of the 2017 election, we consider two types of specificities for voters: 1) their official vote, 2) their age and gender characteristics.

In the official vote, one correlation is uncontroversial: the more the official vote corresponds to populist or protest voting, the higher the axis score. The average number of unapproved candidates inserted between approved candidates, i.e. the intensity of non-conformity, is low in multi-approval ballots completed by electors who voted for Hamon, Macron or Fillon in the official vote (from 0.59 to 0.71 , see Table C.3 in Appendix C). Hence conformity is high for the socialist, centrist and conservative candidates, all of whom had recently been ministers, which means that they embody a certain continuity of the political system. Conversely, for those voters supporting the extreme left-wing candidates (Mélenchon, Poutou, Arthaud) and the populist right (Le Pen, Dupont-Aignan), the average number of unapproved candidates, i.e. the intensity of contradiction to a left-right axis, is enhanced, and ranges from 0.91 to 1.82 . Their vote expresses the will for radical change in politics through people and parties distinct from past governments. The metric of non-conformity is even higher (more than 3 ) for those 16 
uncovered candidates (Lassalle, Cheminade, Asselineau) whose vote is often associated with a protest vote.

Now considering individual characteristics, an interesting finding is that there is no significant difference between men and women: the score axis is about the same for the two groups. As for Le Pen, these results confirm findings by Mayer (2015) for the 2012 election and by Amengay, Durovic, Mayer (2017): the gender gap observed when the Front candidate was Jean-Marie Le Pen does not hold for Marine Le Pen (his daughter) if participation is high enough.

On the other hand, there are differences in voting behavior related to age (see Table C.4 in Appendix C). In the questionnaire associated with the experiment voters have been divided into 5 age groups: 1829 years old, 30-39 years old, 40-49 years old, 50-59 years old, 60-69 years old and 70 years old and over. We can observe various trends that create a more nuanced analysis of old and new generations. Firstly, the proportion of mono-approval ballots almost strictly increases with age. This proportion, only $16 \%$ among 18-29 year olds, exceeds $29 \%$ for those who are 70 and over. This generation gap could be interpreted as resulting from an established habit among older people of voting for a single candidate. On the other hand, differences in the nature of the mono-approved candidates express a changing demand among voters. Four candidates are sufficiently mono-approved for clear trends to emerge; they are viable candidates (see Table C.5 in Appendix C). The older the voter, the more significant the proportion of mono-approval for the two candidates who represent the traditional political spectrum of government parties: Macron and Fillon. On the contrary, populist candidates on the right and on the left (Le Pen and Mélenchon) correspond more frequently to a unique choice on the part of young voters. Secondly, the axis discrepancy rate varies across ages (see Table C. 4 Appendix C). This proportion is high among 18-29 year old (at 45.63\%); it decreases sharply in the 30-49 age group (up to $37.47 \%$ and $40.25 \%$ ); increases between 50 and 69 years (44.12\% and 50.78\%); and is significantly lower for those aged 70 and over (35.61\%). Such variations with age may be due to pure chance. But we wish to suggest another possible interpretation: non-conforming ballots and protest votes tend to change in step with the economic and social difficulties encountered by the different cohorts. The age groups for which there are many non-conformities correspond to the beginning and the end of a working life. We know that the youngest (18-29 years old) faces problems of entry to the labor market, and that the end of a working life also faces difficulties: finding a job in the event of dismissal (after the age of 50) and, more recently, in the transition to retirement (around the age of 62), a transition which became less favorable than it had been for previous generations. By contrast, the other age groups generally correspond to the most stable part of a working life (from the age of 30 to 49), or to a more favorable and predictable situation (aged 70 years old and over). In favor of this thesis of a contrast in cohorts' experience of finding work and facing retirement is the relatively high non-conformity rate of the 50-69 years olds, who are also those whose strong support for the "yellow vests" - "Les gilets jaunes" movement has been wellpublicised (See Algan 2018).

17 
Thirdly, this new perspective still supports the argument that the established left-right axis that had structured politics for decades is breaking down, both for present and for new generations. The score axis calculated on the only results that show non-conformity with the axis decreases as age increases (see Table C. 4 in Appendix C): it ranges almost continuously from 2.56 for the youngest to 2.08 for those 70 and over. The younger the voters, the more likely they are to vote at the same time for distant candidates on our axis. We consider this to be an indication that reference to an established political camp has less and less force in decision-making.

Finally, despite the way in which we have represented choices on a left-right axis, this seems no longer to be a general point of reference for many when considering the political landscape. This shift in perception of the political landscape not only derives from new generations but, it could be said, from the problems faced by older people that former governments have failed to resolve.

\section{Conclusion}

Our paper aimed to reassess the story of the 2017 French presidential election via the novel perspective of approval voting. We claim that the focus on official ballot data, including surveys of the official vote, probably suppresses a great deal of relevant information on individual political preferences and the dynamic of French politics. We consider at least two reasons why the official ballot is not likely to be completely reliable as a guide to voters' preferences. Firstly, as voters only pick one name when voting under the official rule, they have no way of expressing their preferences with respect to all candidates. The fact that a candidate is voted for does not tell us very much about what the voter thinks of the other candidates. Secondly, the strong incentive to strategic voting undermines the quality of information on preferences contained in the ballots: the fact that a candidate is not voted for does not imply rejection. We argue that alternative voting rules like approval voting, to the extent that the ballot technology permits multiple choices, provide more complete and less biased information on voters' political preferences.

After outlining the political background to the first round of the official election, we analyzed experimental data on approval voting in relation to the official results. We have drawn attention to three main features of the Presidential election contest likely to shed light on important political dynamics in Western Europe more generally. Firstly, we have been able to demonstrate that the observed decline of historical parties such as the conservative or the socialist party is accentuated by the official voting system and a change in voting practice. The official voting system had artificially protected traditional parties for some years, but it now discriminates against them; we should not interpret their sudden fall in popularity as a substantial discontinuity in voter support. The discontinuity is owed to the voting rule, which may have concealed a more profound and long-term change in the electorate. Rather than a rejection of the candidates of traditional government parties, electors show greater freedom of mind: 
their vote is no longer automatically acquired by a party regardless of its candidate. This situation allowed a charismatic individual to create a new party and come to power. The strategic aspects of the official vote reduce the voting-share of historical parties when their candidate becomes non-viable. Secondly, these experimental results modify the thesis of a rightward shift in French society that commentary sometimes supports. Instead, they show that leftist candidates remain paradoxically attractive for the majority of voters, including a very high proportion of those who vote for right-wing candidates in the official vote. Thirdly, despite the political axis that we derived, the data confirm a persistent impression of a major reorganization of the political landscape: of change in the practices of candidates as well as in the political perception of voters. Voters, and more particularly younger voters, as well as the electorate under 30 and between 50 and 65 , are progressively abandoning the traditional left-right non-populist structure of politics. While the election of Macron, a centrist former minister, was unexpected in other countries, we can show that this was not an exception to an established trend, but rather confirmed or even reinforced a trend.

\section{References}

Algan, Yann and Beasley, Elizabeth and Cohen, Daniel and Foucault, Martial (2018) The Rise of Populism and the Collapse of the Left-Right Paradigm: Lessons from the 2017 French Presidential Election (August 2018). CEPR Discussion Paper No. DP13103. Available at SSRN: https://ssrn.com/abstract=3235586

Amengay, A., Durovic, A. \& Mayer, N. (2017) L'impact du genre sur le vote Marine Le Pen. Revue française de science politique, 67(6): 1067-1087. doi:10.3917/rfsp.676.1067.

Baujard, A. \& Igersheim, H. (2009). Expérimentation du vote par note et du vote par approbation le 22 avril 2007 : Premiers résultats. Revue économique, 60(1): 189-201. doi:10.3917/reco.601.0189.

Baujard, Antoinette and Herrade Igersheim (2011) A Framed-field experiment on Approval voting and Evaluation voting". in Bernard Grofman, Annie Laurent and Bernard Dolez (Eds.), In situ and Laboratory Experiments on Electoral Law Reform: French Presidential Elections, Heidelberg: Springer Science, Series Studies in Public Choice 25, chap.4: 69-89.

Baujard, Antoinette, Herrade Igersheim and Isabelle Lebon (2020) Some regrettable grading scale effects under different versions of evaluative voting. Should be soon published as a WP GATE or Condorcet Paper at CREM.

Baujard, Antoinette, Herrade Igersheim, and Thomas Senné (2011) The Political Supply in the 2007 French Presidential Elections: An Analysis Based on Experimental Data. Annals of Economics and Statistics / Annales d'Économie et de Statistique, 101/102 : 149-186.

Baujard, Antoinette, Herrade Igersheim, Isabelle Lebon, Frédéric Gavrel and Jean-François Laslier (2014) “Who is favored by evaluative voting: an experiment conducted during the 2012 French presidential election" Electoral Studies 34: 131-145. 
Bouveret, Sylvain, Renaud Blanch, Antoinette Baujard, François Durand, Herrade Igersheim, Jérôme Lang, Annick Laruelle, Jean-François Laslier, Isabelle Lebon, Vincent Merlin (2019) Voter Autrement 2017 for French Presidential Election — The In Situ Experiments Voting Material.

Darmann, Andreas, Julia Grundner and Christian Klamler (2017) How voters use grade scales in evaluative voting. Public Choice 173(1): 201-216.

Ferrand, Alexis (2019) Des préférences politiques contradictoires avant l'élection présidentielle de 2017. 2019. halshs-01971012.

Ehrhard, T. (2016) Le Front national face aux modes de scrutin : entre victoire sous conditions et influences sur le système partisan. Pouvoirs, 157(2): 85-103. doi:10.3917/pouv.157.0085.

Haegel, Florence (2019) Le grand chambardement des systèmes partisans. La Vie des idées, 8 avril 2019. ISSN : 2105-3030.

URL : http://www.laviedesidees.fr/Le-grand-chambardement-des-systemes-partisans.html

Kriesi Hanspeter, Edgar Grande, Romain Lachat, Martin Dolezal, Simon Bornschier, Timetheos Frey (2006) Globalization and the Transformation of the National Political Space: Six European Countries Compared. European Journal of Political Research, 45(6):921-956.

Lachat, Romain (2008) 'The impact of party polarization on ideological voting'. Electoral Studies 27(4): 687-698

Lachat, Romain (2018) 'Which way from left to right? On the relation between voters' issue preferences and leftright orientation in West European democracies'. International Political Science Review, 39(4): 419-435.

Lebon, Isabelle, Antoinette Baujard, Herrade Igersheim, Frédéric Gavrel, Jean-François Laslier (2017) ‘Ce que le vote par approbation révèle des préférences des électeurs français', Revue économique, 6(68): 1063-1076.

Martin, Pierre (2017) Un séisme politique. L’élection présidentielle de 2017. Commentaire, 158(2) : $249-264$.

Mayer, Nonna (2015) The Closing of the Radical Right Gender Gap in France ? French Politics, 13 (4): $391-414$.

Meguid, Bonnie (2005) Competition Between Unequals: The Role of Mainstream Party Strategy in Niche Party Success. American Political Science Review, 99(3): 347-359.

Meguid, Bonnie (2008) Party Competition between Unequals: Strategies and Electoral Fortunes in Western Europe. Cambridge: Cambridge University Press.

Norris P. and Inglehart R (2018) Cultural Backlash: Trump, Brexit, and The Rise of Authoritarian Populism, Cambridge University Press.

Rose, Michel (2016) French do not want Hollande-Sarkozy re-match in 2017; poll. Reuters, 2 Janvier. https://www.reuters.com/article/us-france-politics-poll/french-do-not-want-hollande-sarkozy-re-matchin-2017-poll-idUSKBNOUG0HF20160102.

Tiberj, Vincent (2012) Two-axis politics. Values, votes and sociological cleavages in France (1988-2007). Revue française de science politique, 62(1): 71-106. 
Tiberj, Vincent (2013) The times they are a-changing : generational renewal and political transformations in France. Revue française de sociologie, 54 (4): 741-776.

Tiberj, Vincent, Bernard Denni, Nonna Mayer (2013) One choice, multiple reasons. Political preferences, the space of possibilities and votes in 2012. Revue française de science politique, 63(2): 249-278.

\section{Data base in free access}

Bouveret, Sylvain, Renaud Blanch, Antoinette Baujard, François Durand, Herrade Igersheim, Jérôme Lang, Isabelle Lebon, Annick Laruelle, Jean-François Laslier and Vincent Merlin (2019) Voter Autrement 2017 for the French Presidential Election - The data of the In Situ Experiment. Zenodo. http://doi.org/10.5281/zenodo.3548677 


\section{Appendix A - The experimental design}

On April 23, 2017, the day of the first round of the French presidential election, voters at several polling stations in four French municipalities were asked to take part in an experiment involving alternative voting rules.

The data we use in this paper come from the following four municipalities:

- Hérouville-Saint-Clair, a city in northern-western France (Normandy Region), is a somewhat working-class suburb of a larger city, Caen. Two polling stations in this city were involved in the 2017 experiment.

- Strasbourg is a large city in the north-east of France (GrandEst Region, formerly Alsace) which hosts the European Parliament. The two polling stations involved in the 2017 experiment are located in the city center.

- Grenoble is a large city located in the south-east of France (Auvergne-Rhône-Alpes Region); the three voting stations involved in the 2017 experiment are located in the city center.

- Crolles, located in the south-east of France (Auvergne-Rhône-Alpes Region) close to Grenoble, is a residential town. Each of its six polling stations hosted the 2017 experiment.

The variety of the locations does not imply a representative sample of the French electorate. However the wide range in geographical, political, and sociological context of the these polling stations provides information on a broad range of participants, and furthers our capacity to correct data.

In each of the voting stations, voters were asked to volunteer for an experimental ballot after they had cast their official vote in a format that exactly reproducing the organization of the official vote, but with different ballot papers. Voters filled experimental ballots in a voting booth guaranteeing voter anonymity, placed it in a standard envelope, and dropped it into as ballot box. It is noteworthy that 50,01 $\%$ of voters who turned up for the official vote ended up participating in the experimental vote.

The experimental ballots offered the opportunity of testing two alternative voting methods, one of which was approval voting (see the voting material in Bouveret et al. 2017). It also contained a questionnaire where participants could indicate their official vote and some individual characteristics, such as gender and age (and other characteristics in some voting stations). The proportion of ballots where questionnaires were filled for all three elements was as high as 70,46\%. Hence the importance of the data yielded and the diversity of the places where it was collected.

\section{Appendix B - Presentation of data}

The approval data used in this study come from an in situ experiment conducted jointly at the polling stations of four urban areas (see Appendix A). Our study can only take into account a subset of the information yielded by the experimental ballots, hence we focus on ballots for which the official vote 
and and the demographic data of the participant is indicated (see Appendix A), and where the latter is a vote cast (hence no blank or spoiled votes) so that it is clearly politically oriented. The distribution of ballots by site is given in Table B.1.

Table B.1 : Distribution of ballots by site

\begin{tabular}{|l|l|l|}
\hline Experiment site & Number of ballots & $\begin{array}{l}\text { Number of usable ballot papers } \\
\text { (with a ballot cast in official voting) }\end{array}$ \\
\hline Hérouville-Saint-Clair & 644 & 634 \\
\hline Strasbourg & 935 & 915 \\
\hline Grenoble & 1024 & 1019 \\
\hline Crolles & 1250 & 1244 \\
\hline Total & $\mathbf{3 8 5 3}$ & $\mathbf{3 5 1 2}$ \\
\hline
\end{tabular}

In this sample the distribution of choices that participants gave for the official vote is not completely in line with the results of the first round (see Table B.2). The experimental ballots must therefore be weighted so that the distribution of the declared results for the official ballots reproduces that of the official vote (see Table B.2):

Table B.2 : Weight per candidates to correct data

\begin{tabular}{|c|c|c|c|c|c|c|c|c|c|c|c|}
\hline & EM & MLP & FF & JLM & BH & NDA & JL & PP & FA & NA & JC \\
\hline Sample & 33.18 & 4.62 & 10.97 & 30.85 & 14.98 & 2.81 & 0.60 & 0.76 & 0.71 & 0.42 & 0.10 \\
\hline $\begin{array}{c}\text { Off. } \\
\text { voting }\end{array}$ & 24.01 & 21.30 & 20.01 & 19.58 & 6.36 & 4.70 & 1.21 & 1.09 & 0.92 & 0.64 & 0.18 \\
\hline Weight & 0.7235266 & 4.6133863 & 1.8248354 & 0.6346850 & 0.4245940 & 1.6744299 & 2.0054435 & 1.4327862 & 1.2989037 & 1.5248 & 1.7154 \\
\hline
\end{tabular}

To be read as: $33.18 \%$ of the participants in the experiment stated that they had chosen Emmanuel Macron in the official voting, whereas he obtained only $24.01 \%$ of the votes of the first round. Official votes declared for Emmanuel Macron in the experimental ballot are therefore weighted by 0.7235 to correct the data.

All the corrected data in this article incorporate this weighting of experimental ballots. 


\section{Appendix C - Co-approvals between the candidates and characteristics of}

\section{the left-right axis}

Table C.1. Table of co-approvals (in \% of the voters who approve the candidate in line)

\begin{tabular}{|c|c|c|c|c|c|c|c|c|c|c|c|}
\hline & EM & MLP & FF & JLM & BH & NDA & JL & PP & FA & NA & JC \\
\hline EM & 100 & 14.92 & 33.86 & 35.30 & 43.27 & 16.33 & 7.06 & 10.57 & 4.26 & 5.95 & 3.07 \\
\hline MLP & 24.60 & 100 & 37.71 & 23.54 & 7.96 & 38.85 & 8.11 & 7.36 & 10.10 & 6.10 & 3.72 \\
\hline FF & 51.21 & 34.59 & 100 & 15.06 & 14.00 & 32.04 & 7.48 & 3.90 & 5.61 & 2.47 & 3.29 \\
\hline JLM & 41.46 & 16.77 & 11.70 & 100 & 59.57 & 13.66 & 8.26 & 30.95 & 7.11 & 16.42 & 4.37 \\
\hline BH & 55.21 & 6.16 & 11.81 & 64.72 & 100 & 9.91 & 8.25 & 26.74 & 4.66 & 15.15 & 4.17 \\
\hline NDA & 35.25 & 50.85 & 45.72 & 25.10 & 16.77 & 100 & 12.14 & 8.81 & 13.56 & 6.80 & 7.42 \\
\hline JL & 43.66 & 30.44 & 30.59 & 43.51 & 40.01 & 34.79 & 100 & 26.64 & 18.98 & 16.93 & 17.65 \\
\hline PP & 31.61 & 13.35 & 7.71 & 78.82 & 62.68 & 12.21 & 12.88 & 100 & 9.07 & 39.03 & 6.35 \\
\hline FA & 31.77 & 45.70 & 27.67 & 45.18 & 27.27 & 46.90 & 22.89 & 22.63 & 100 & 17.45 & 23.23 \\
\hline NA & 31.69 & 19.70 & 8.70 & 74.47 & 63.27 & 16.80 & 14.58 & 69.53 & 12.46 & 100 & 7.14 \\
\hline JC & 39.22 & 28.96 & 27.88 & 47.68 & 41.90 & 44.70 & 36.57 & 27.22 & 39.91 & 17.19 & 100 \\
\hline
\end{tabular}

To be read as: The proportion of EM-approved voters who also approve MLP is $14.92 \%$.

The distance between two contiguous candidates on the axis is inversely proportional to the average of the co-approvals between these two candidates. More precisely, this distance is equal to 1 minus this average. Thus two candidates who would always be approved simultaneously would be exactly on the same point of the axis, the distance between them being zero. For example, the distance between Arthaud and Poutou is here equal to:

$1-(0.6953+0.3903) / 2=0.4572$. 
Table C.2. Distances between contiguous candidates on the left-right axis

\begin{tabular}{|l|l|l|l|l|l|l|l|l|}
\hline $\begin{array}{l}\text { Distance } \\
\text { NA to PP }\end{array}$ & $\begin{array}{l}\text { Distance PP } \\
\text { to JLM }\end{array}$ & $\begin{array}{l}\text { Distance } \\
\text { JLM to BH }\end{array}$ & $\begin{array}{l}\text { Distance } \\
\text { BH to EM } \\
\text { EM to FF }\end{array}$ & $\begin{array}{l}\text { Distance } \\
\text { to MLP }\end{array}$ & $\begin{array}{l}\text { Distance } \\
\text { NDPA }\end{array}$ & $\begin{array}{l}\text { Distance } \\
\text { NDA to J1 } \\
\text { to }\end{array}$ & $\begin{array}{l}\text { Distance JL } \\
\text { to FA }\end{array}$ \\
\hline 0,4572 & 0,45115 & 0,37855 & 0,5076 & 0,57465 & 0,6385 & 0,5515 & 0,76535 & 0,79065 \\
\hline
\end{tabular}

Table C.3. Average number of unapproved candidates inserted between approved candidates on multi-approval ballots according to the official voting

\begin{tabular}{|c|c|c|c|c|c|c|c|c|c|c|}
\hline $\begin{array}{c}\text { Official } \\
\text { voting } \\
\text { candidate }\end{array}$ & EM & MLP & FF & JLM & BH & NDA & JL & PP & FA & NA \\
\hline & 0.66 & 1.29 & 0.71 & 0.91 & 0.59 & 1.82 & 3.65 & 1.12 & 4.38 & 0.92 \\
\hline
\end{tabular}

Table C.4. Characteristics of approval behavior by age group

\begin{tabular}{|c|c|c|c|c|c|c|}
\hline Age group & $18-29$ & $30-39$ & $40-49$ & $50-59$ & $60-69$ & 70 and + \\
\hline Proportion of mono-approval & $16.05 \%$ & $19,63 \%$ & $21.25 \%$ & $20,52 \%$ & $24.29 \%$ & $29.40 \%$ \\
\hline $\begin{array}{l}\text { Rate of ballots consistent with } \\
\text { the axis* }\end{array}$ & $54.37 \%$ & $62.43 \%$ & $59.75 \%$ & $55.88 \%$ & $49.22 \%$ & $64.39 \%$ \\
\hline $\begin{array}{l}\text { Average number of } \\
\text { nonconformity in ballots non- } \\
\text { consistent with the axis }\end{array}$ & 2.56 & 2.39 & 2.25 & 2.12 & 2.19 & 2.08 \\
\hline
\end{tabular}

*Among the multi-approval ballots.

Table C.5. Proportion of each viable candidate in the mono-approval ballots by age group

\begin{tabular}{|l|l|l|l|l|l|l|}
\hline Age group & $18-29$ & $30-39$ & $40-49$ & $50-59$ & $60-69$ \\
\hline EM & $22.02 \%$ & $22.92 \%$ & $27.36 \%$ & $31.72 \%$ & $34.26 \%$ \\
\hline MLP & $23.12 \%$ & $28.26 \%$ & $28.80 \%$ & $25.78 \%$ & $17.41 \%$ & $14.07 \%$ \\
\hline FF & $16.76 \%$ & $16.63 \%$ & $18.99 \%$ & $11.93 \%$ & $24.98 \%$ & $37.69 \%$ \\
\hline JLM & $18.55 \%$ & $13.22 \%$ & $11.01 \%$ & $14.27 \%$ & $11.58 \%$ & $8.55 \%$ \\
\hline
\end{tabular}

